\title{
Comment on Sewell and Eastwood: Screening and treatment in developmental dysplasia of the hip-where do we go from here?
}

\author{
Cheng-Wei Wang
}

Received: 2 April 2012 / Accepted: 8 April 2012 /Published online: 28 April 2012

(C) Springer-Verlag 2012

Dear Sir,

After reading the article by Sewell and Eastwood entitled "Screening and treatment in developmental dysplasia of the hip-where do we go from here?" [1], I found there may be an error. To make the classification more clear, the table should read:

Graf $2 \mathrm{~b}: 50^{\circ} \leqq \alpha$-angle $<60^{\circ}[2]$ instead of Graf $2 \mathrm{~b}: 43^{\circ} \leqq \alpha-$ angle $<60^{\circ}$.

Besides, the $\beta$ angle also has a typing error in the table when describing Graf $2 \mathrm{c}$ and $2 \mathrm{~d}$ hips. The table should read:
Graf 2c: $43^{\circ} \leqq \alpha$-angle $\leqq 49^{\circ}, \beta$-angle $<77^{\circ}$

Graf 2 d: $43^{\circ} \leqq \alpha$-angle $\leqq 49^{\circ}, \beta$-angle $>77^{\circ}$

\section{References}

1. Sewell MD, Eastwood DM (2011) Screening and treatment in developmental dysplasia of the hip-where do we go from here? Int Orthop 35:1359-1367

2. Wientroub S, Grill F (2000) Ultrasonography in developmental dysplasia of the hip. J Bone Joint Surg Am 82:1004-1018

C.-W. Wang $(\bowtie)$

Department of Orthopaedic Surgery, College of Medicine,

National Taiwan University \& Hospital,

No. 7, Chung-Shan South Road,

Taipei 10043 Taiwan, People's Republic of China

e-mail: janeway.wang@gmail.com 